\title{
Green chemistry and the biorefinery concept
}

\author{
Ana RC Morais and Rafal Bogel-Lukasik ${ }^{*}$
}

\begin{abstract}
Green Chemistry and Biorefinery concepts are two approaches helping to develop new and more sustainable processes. The implementation of both methodologies impels to fossil-independent future with bioeconomy based on natural feedstock like biowaste and industrial by-products. The development of technologies for valorisation of these resources is a key role of society in the creation of sustainable and more environmentally friendly future.
\end{abstract}

Keywords: Green chemistry, Biorefinery concept, Value added products

\section{Background}

More than 20 years passed since the Rio Declaration on Environment and Development was signed. Still nowadays, the declaration is valid and indicates the role of sustainability for the future of mankind. The first principle of this declaration states that Human beings are at the centre of concerns for sustainable developments, they are entitled to a healthy and productive life in harmony with Nature [1]. This principle highlights the objectives of sustainable developments and establishes challenges to offer technological, scientific and social tools to fulfil these goals. Shortly after the Rio Declaration, Anastas and Warner presented 12 Principles of Green Chemistry [2] but more a decade before Trevor Kletz in his Jubilee lecture entitled "What you don't have, can't leak" [3] draw the frames in which scientific and industrial work should be performed. This basis of green chemistry created a fundament for further development and implementation of Anastas and Warner principles of green chemistry. One of these frames is integration of green chemistry principles in the biorefinery concept. Among the several definitions of biorefinery, the most widely used and recently accomplished by International Energy Agency (IEA) Bioenergy Task 42 is "Biorefining is the sustainable processing of biomass into a spectrum of marketable products and energy". The biorefinery is an industrial facility (or network of facilities) that cover an extensive range of combined technologies aiming to full sustainable transformation of biomass into their building blocks with the concomitant production of biofuels, energy, chemicals and materials, preferably of

\footnotetext{
* Correspondence: rafal.lukasik@lneg.pt

Laboratório Nacional de Energia e Geologia, Unidade de Bioenergia, 1649-038, Lisboa, Portugal
}

added-value [4]. The biorefinery concept embraces a whole crop approach of biomass conversion pathways leading to a whole portfolio of valuable products, drawing direct similarities to today's fossil oil refineries, in which multiple fuels, basic chemicals, intermediate products and sophisticated products are produced from petroleum $[5,6]$. To accomplish these needs science developed many less energy-requiring and less waste-generation technologies. However, still need of a new investment requirements and a perceived high risk of adoption of new technologies are slowing down the implementation of new processes. The solution of this problem is the development of more sustainable technologies that significantly increase the resource efficiency of chemical processes and reduce the operation time of such technologies. In addition, these new technologies should be accomplished in chemical industries by the introduction of chemical processes that do not produce contaminants, but only non-toxic commodities and recyclable or easily degradable materials. Industries should be based on ideal processes that start from non-polluting starting materials, lead to no secondary or concomitant products and require no solvents in order to carry out any chemical conversion or to isolate and purify the product. Such intrinsically clean processes seem still hardly attainable at present. But it is expected from the ingenuity and resourcefulness of chemists that the chemical industry replaces many existing processes with new technologies aiming at a zero environmental footprint. This is important for fine and pharmaceutical industries which use energy [7] and generate a significant amount of chemical waste. However it is probably even more important for large chemical industries which a few minutes carbon footprint equals a yearly carbon footprint of pharma 
enterprise [8]. The waste and energy problems must be solved in the near future because the waste generation and energy consumption are increasing strongly due to growth of the world population and increasing standards of living in emerging economies [9].

Europe will need to ensure sufficient and sustainably produced supplies of raw materials, energy and industrial products, under conditions of decreasing fossil carbon resources while maintaining its competitiveness. Bio-waste (estimated at up to 138 million tonnes per year in the Union, of which up to $40 \%$ is land-filled) represents a huge environmental problem and cost, despite demonstrating its great potential. Major changes are needed to reduce this amount by $50 \%$ in the Union by 2030 [10]. The way to solve this is to boost sustainable bioproducts, intermediates and bioenergy/biofuels, predominantly focussing on a cascade approach, prioritising the generation of high added-value products in the biorefinery concept [11]. Enhancing the range of types of biomass for use in second and third generation biorefineries, including forestry, biowaste and industrial by-products [12]. This will guide to new economy making society in the larger extend independent on fossil resources. The knowledge based bioeconomy includes excellence in science, technology and industry to deliver innovation, world leadership in food technologies and products and animal breeding technologies, and having a strong chemical and manufacturing industry base. The synergy between all these factors is strongly required and should be structured on the key word knowledge based. The stimulation for these collaborations are large R\&D\&D projects The European Commission has funded several projects under last two framework programmes and in the near future continuous support is foreseen in the frame of HORIZON 2020. The strong mutual interactions between industry and academia started to give benefits and increasing number of biorefinery oriented research programmes are made. Among the largest projects supported from national and European funds are Biomass Energy Europe, Sustoil, Star-COLIBRI, Biocore, EuroBioRef and so on. These projects tackle very wide aspects of biorefinery industry and trying to overcome the technological and legislative bottlenecks. The major social barriers to be still overwhelmed are: i) the pressure on water, ii) the social and demographic progress and its impact on industry sectors, iii) the climate changes, iv) the alterations in lifestyles and eating habits, v) the demand for safer and healthy food, vi) the needs to stop the continuously increase demand on food and fuel, vii) the control and prevention of diseases development. These are only some social awareness which in a short term will require concrete responses. Therefore more active work in this field is strongly desired and it can be achieved by the integration of policy for the knowledge based bioeconomy, research and innovation, more effective integration of various life sectors, industry and academia, broad communication and education programmes to dispel the myths about the negative impact of chemistry on our life and about the real challenges for society and support for low carbon footprint either food or energy directed processes. Biorefineries might and should play a vital role in solving some of these hot problems. By working together synthetic biologists, engineers and green chemists can undoubtedly help boost the case for bio-based technologies by seeing wastes as not a problem but as an opportunity for new product.

Although the implementation of the biorefinery concept in the chemical industry is on-going process still the industrial biorefineries are rare examples. Nevertheless the development of biorefineries in Europe, USA and Brazil shows the positive trend that can be copied and spread in various industry sectors around the world. A sugar cane mills are at the present moment a modest biorefinery producing few products such as sugar, ethanol and value added products such as polyhydroxybutyrate [13]. It is foreseen that in the near future this industry can expand its production using several renewable feedstock's to produce biofuels and high value biobased chemicals. Other known examples of currently running biorefineries or their prototypes are pulp industries such as Lenzing AG (Austria), Portucel Soporcel (Portugal), Zellstoff Stendal (Germany) or companies using agriculture residues as INBICON (Denmark), Ensyn (Canada), Cristal Union (France) or DuPont (USA) to produce energy products and value added commodities. The continued development of these and other biorefineries will lead to a greater variety of feedstocks, technologies and co-products and will add value to the sustainable use of biomass, maximises biomass conversion efficiency minimising raw material requirements, produces a spectrum of bio-based products and bioenergy and will make a significant contribution to sustainable development, challenging national, European and global policy goals for strengthening of the economic position of various market sectors [14].

The employment of green chemistry principles mentioned above into the biorefineries can make a significant contribution to sustainable development by adding value to the sustainable use of biomass. A wide spectrum of bio-based products and bioenergy can be obtained feeding the full bio-based economy constructed on multi-disciplinary partnerships to foster necessary $R \& D \& D$ direction having as a key point principles of green chemistry.

\section{Competing interest}

The authors declare that they have no competing interests.

\section{Authors' contribution}

Both authors contributed to the writing of the manuscript. Both authors read and approved the final manuscript. 


\section{Acknowledgements}

Authors gratefully acknowledge funding under COST TD1203 Action.

Received: 11 July 2013 Accepted: 10 September 2013

Published: 23 September 2013

\section{References}

1. United Nations: Rio declaration on environment and development. Rio de Janeiro, Brazil: United Nations; 1992.

2. Anastas PT, Warner JC: Green chemistry: theory and practice. New York: Oxford University Press; 1998.

3. Kletz T: What you don't have, can't leak. Chem Ind 1978:287-292.

4. The Ibero-American Society for the Development of Biorefineries. www.siadeb.org.

5. Fernando S, Adhikari S, Chandrapal C, Murali N: Biorefineries: current status, challenges, and future direction. Energy Fuel 2006, 20:1727-1737.

6. Cherubini F: The biorefinery concept: using biomass instead of oil for producing energy and chemicals. Energy Convers Manag 2010, 51:1412-1421.

7. Worcell E, Phylipsen D, Einstein D, Martin N: Energy Use and energy intensity of the US chemical industry. Berkley, USA: University of Berkley; 2000.

8. Wasserscheid P: Foresight lecture. In 6th International Conference on Green and Sustainable Chemistry; 7 August 2013. Nottingham; 2013.

9. Energy Information Administration: International energy outlook 2004. Washington, DC, USA: US Department of Energy; 2004.

10. European Commission: HORIZON2020 - Proposal for a council decision establishing the specific programme implementing horizon 2020-the framework programme for research \& innovation (2014-2020). part III - societal challenges. Brussels; 2013.

11. Bozell JJ, Petersen GR: Technology development for the production of biobased products from biorefinery carbohydrates-the US department of Energy's "Top 10" revisited. Green Chem 2010, 12:539-554.

12. Luque $\mathrm{R}, \mathrm{Clark} J \mathrm{H}$ : Valorisation of food residues: waste to wealth using green chemistry technologies. Sustainable Chemical Processes 2013, 1:10.

13. Rodrigues JAR: Do engenho à biorrefinaria: a usina de açúcar como empreendimento industrial para a geração de produtos bioquímicos e biocombustíveis. Quim Nova 2011, 34:1242-1254.

14. de Jong E: Biorefineries: adding value to the sustainable utilisation of biomass. International Energy Agency 2009, T42:2009:01:1-16.

doi:10.1186/2043-7129-1-18

Cite this article as: Morais and Bogel-Lukasik: Green chemistry and the biorefinery concept. Sustainable Chemical Processes 2013 1:18.

Publish with ChemistryCentral and every
scientist can read your work free of charge
"Open access provides opportunities to our
colleagues in other parts of the globe, by allowing
anyone to view the content free of charge."
W. Jeffery Hurst, The Hershey Company.
- available free of charge to the entire scientific community
- peer reviewed and published immediately upon acceptance
- cited in PubMed and archived on PubMed Central
- yours - you keep the copyright
Submit your manuscript here:
http://www.chemistrycentral.com/manuscript/

